\title{
Aclasta effectively treats osteoporosis in patients with femoral head fractures
}

\author{
V.T. Toan and B.V. Anh \\ Chi Minh city, Vietnam \\ Corresponding author: V.T. Toan \\ E-mail: vothanhtoan1990@yahoo.com \\ Genet. Mol. Res. 20 (1): gmr18744 \\ Received December 30, 2019 \\ Accepted April 20, 2020 \\ Final Revision January 25, 2021 \\ Published March 30, 2021 \\ DOI http://dx.doi.org/10.4238/gmr18744
}

Department of Orthopedics and Trauma Surgery, Thong Nhat Hospital, Ho

\begin{abstract}
We assessed the effectiveness of Aclasta for osteoporosis in patients with femoral head fractures at Thong Nhat Hospital in Ho Chi Minh City. A total of 156 patients with femoral head fractures and osteoporosis in the orthopedic department at Thong Nhat in Ho Chi Minh City were assigned to a randomized controlled trial from 01 Jan 2013 to 01 Jan 2014, divided into two groups: 75 patients were treated with Aclasta; 81 patients received a placebo. Most of them were followed for at least one year for new bone fractures and $\mathrm{T}$-score index before and one year after treatment. New fractures were found at a rate of about $8 \%$ in the Aclasta group and $13.6 \%$ in the placebo group, which was significantly different $(\mathrm{P}<0.001)$. Vertebral fractures were different in Aclasta (1.3\%) and Placebo groups $(3.7 \%)$, and the incidence of femoral head fracture was 2.6 and $3.7 \%$. T-score improved significantly after one year in the Aclasta group; the proportion of patients with a $\mathrm{T}$ score in this group changed due to bone deficiency 33.3 and $8 \%$, while in the placebo group, it was 7.4 and $0 \%$; this difference was significant (p $<0.001)$. Using Aclasta for treatment of osteoporosis after femoral head fracture surgery reduces the incidence of new fractures and gives T-score improvement in patients with femoral head fractures, especially in elderly patients.
\end{abstract}

Key words: Osteoporosis; Postmenopausal osteopenia; Bone density; Fractures; Zoledronic acid 


\section{INTRODUCTION}

Osteoporosis is defined as a type of impaired metabolism in bone tissue, which is characterized by a progressive decrease in fully functioning bone mass. The peculiarity of osteoporosis is a decrease in bone mineral density and its destruction. Osteoporosis is typical for women in the climacteric period, which is associated with a decrease in ovarian function. Also, an increase in the incidence of osteoporosis is observed in older men.

The symptoms of osteoporosis, generally speaking, are from the fractures they cause. New fractures after surgery on femoral head fractures in osteoporotic patients lead to a failure of treatment. Treatment with Aclasta (zoledronic acid) - an intravenous bisphosphonate - for osteoporosis once a year can improve this situation (Black et al., 2006, 2010; Nguyen et al., 2006; Siris et al., 2006; Lyles et al., 2007). Aclasta is given as an infusion during at least 15 minutes. Aklasta inhibits the processes of bone resorption, which subsequently contributes to the restoration of bone mass. Aklasta is also used in the treatment of Paget's disease, in which case each dose administered is effective for about a year. One vial of this drug contains about $5 \mathrm{mg}$ of zoledronic acid.

Most side effects of Aclasta are mild to moderate and occur within the first three days of administration. Patients should be advised about the post-dose symptoms that are commonly seen following administration of an intravenous bisphosphonate. These include flu-like symptoms such as fever, myalgia, flu-like illness, headache, and arthralgia (European Med. Agency, 2015; Hayer et al. 2017; Miller et al. 2017; Reid et al. 2018; Aclasta (zoledronic acid), 1 Oct. 2020; Aclasta, 28 Sep. 2020).

We conducted a study to assess the effectiveness of Aclasta for osteoporosis in patients with femoral head fractures at Thong Nhat Hospital in Ho Chi Minh City because of the large number of elderly patients with osteoporosis, the high rate of femoral head fractures and the high incidence of fractures after surgical interventions.

\section{MATERIAL AND METHODS}

\section{Subjects}

We enrolled 156 osteoporotic patients with femoral head fractures from the Department of Orthopedic Trauma Hospital in Ho Chi Minh City between January 1, 2013 and January 1, 2014. All patients were familiar with the study design and signed an agreement to participate in it. All procedures were in accordance with the ethical standards of the responsible committees on human experiments (institutional and national) and the Declaration of Helsinki, 1975, revised in 2000.

The recommended dose of Aclasta is $5 \mathrm{mg}$ given as an intravenous infusion once a year. Infusions were given by a doctor or nurse over at least 15 minutes. Patients with bisphosphonate sensitivity, creatinine clearance $<30 \mathrm{~mm} / \mathrm{min}$, cancer, metabolic disease, or a predicted survival time of $<6$ months were excluded from the study.

\section{Study design}

This study was a randomized, placebo-controlled trial with at least one-year followup. Patients with femoral head fractures and osteoporosis were randomly assigned to 
receive either an infusion of Aclasta or Placebo after surgery. The most common sites for osteoporotic fractures are the bones of the hip, wrist, and spine. Frequent fractures result in disability and loss of performance. (Ji and $\mathrm{Yu}, 2015$ ).

The femoral head fractures must have been due to small impact force (such as falling while standing or from a low elevation) and the patients must have been able to walk prior to their fractures. Risk factors for osteoporosis are both nonspecific (hormonal imbalance) and specific (the use of glucocorticoids in treatment). Bone loss can occur without any symptoms, until the fracture actually occurs.

We calculated T-score by measuring the bone mineral density of the patients' femoral neck that was not fractured to diagnose osteoporosis. Patients received adequate Calcium and Vitamin D supplements 14 days before the infusion. All patients in Aclasta group must not take any concomitant osteoporosis medications after the infusion. We followed the patients at the department's clinic once a month for the minimum of one year after they were discharged and assessed the following variables:

Baseline characteristics of patients: Gender, age, T-score before the treatment.

New fracture events were monitored at least one year after osteoporosis treatment, except for face and toe fractures.

T-score after one year follow-up.

\section{RESULTS}

\section{Baseline Characteristics of the Patients}

The basic characteristics in the two groups namely Gender, Age, T-score before the treatment were similar ( $\mathrm{P}>0.05$ for all comparisons) (Table 1$)$. The majority of patients were females, because osteoporosis mostly affects older women. All patients had T-score before the treatment of -2.5 or less, which indicates a diagnosis of osteoporosis. The greater the negative number, the more severe the osteoporosis.

Table 1. Description of the characteristics of the study participants on the use of Aclasta in postoperative patients with hip fracture.

\begin{tabular}{llllllll}
\hline \multicolumn{2}{c}{ Gender } & \multicolumn{3}{c}{ Age } & \multicolumn{2}{c}{$\begin{array}{l}\text { T-score before } \\
\text { the treatment } \\
\leq-2.5\end{array}$} \\
\hline $\begin{array}{l}\text { Placebo } \\
(\mathrm{n}=81)\end{array}$ & $20(24.7 \%)$ & $61(75.3 \%)$ & $14(17.3 \%)$ & $19(25.3 \%)$ & $34(41.9 \%)$ & $14(17.3 \%)$ & $81(100 \%)$ \\
$\begin{array}{l}\text { Aclasta } \\
(\mathrm{n}=75)\end{array}$ & $17(22.7 \%)$ & $58(77.3 \%)$ & $12(16 \%)$ & $21(28 \%)$ & $31(41.3 \%)$ & $11(14.7 \%)$ & $75(100 \%)$ \\
$\mathrm{P}$ & $>0.05$ & $>0.05$ & $>0.05$ & $>0.05$ & $>0.05$ & $>0.05$ & $>0.05$ \\
\hline
\end{tabular}

\section{New fractures}

A total of 17 of 156 patients (10.9\%) had new clinical fractures during the study, of whom 11 of $81(13.6 \%)$ were in the placebo group and 6 of $75(8 \%)$ were in the zoledronicacid group (significant difference, $\mathrm{P}<0.001$ ) (Table 2). It can be seen that fractures in Placebo group occurred approximately twice as frequently as in the Aclasta group. The rates 
of a new femoral head fracture were $3.7 \%$ (3 patients) in the placebo group and 2.6\% (2 patients) in the zoledronic acid group $(\mathrm{P}<0.05)$; the rates of a new vertebral fracture were $3.7 \%$ (3 patients) and 1.3\% (one patient), respectively $(\mathrm{P}<0.05)$. The difference in the last two types of fractures is not that great, but the effectiveness Aclasta is obvious. Also, patients with reduced bone mineral density and fractures had significantly increased risk for future fractures.

Our outcomes are consistent with those of the studies by Black et al. (2007) and Lyle et al. (2007).

Table 2. Annual incidence of new fractures in the Aclasta group and in the control group.

\begin{tabular}{|c|c|c|c|}
\hline Type of Fracture & $\begin{array}{l}\text { Placebo }(\mathrm{n}=81) \\
\text { No. of patients }\end{array}$ & Aclasta $(n=75)$ & P Value \\
\hline Any clinical fracture & $11(13.6 \%)$ & $(8 \%)$ & $<0.001$ \\
\hline Femoral head fracture & $3(3.7 \%)$ & $2 \quad(2.6 \%)$ & $<0.05$ \\
\hline Vertebral fracture & $3(3.7 \%)$ & $1 \quad(1.3 \%)$ & $<0.05$ \\
\hline
\end{tabular}

\section{T-score}

There was a significant change in T-score after one year of follow-up in the two groups. The rate of patients $(92.6 \%)$ whose T-score remained at the osteoporosis level (less than -2.5 points) in placebo group was greater than in the Aclasta group (58.7\%). The rate of patients with osteoporosis (index T from -2.5 to -1 ) at baseline to have a transition to osteopenia in the Aclasta group (33.3\%) was greater than in the placebo group (7.4\%) (Table 3). In this case, differences in changing of T-scores were impressive. While none of patients in placebo group made the transition to normal T-scores, there were $6(8 \%)$ in the zoledronic-acid group. These results illustrate the effectiveness of Aclasta. We found similar results in reports by Black et al. (2010), Siris et al. (2006) and Nguyen et al. (2006).

Table 3. T-score after one year in the case group (Aclasta) and the control group (placebo) $(\mathrm{N}=156)$ in bone fracture patients.

\begin{tabular}{lll}
\hline T-score & $\begin{array}{l}\text { Placebo }(\mathbf{n}=\mathbf{8 1}) \\
\text { No. of patients }\end{array}$ & Aclasta $(\mathbf{n}=\mathbf{7 5})$ \\
\hline Osteoporosis (Less than -2.5$)$ & $75(92.6 \%)$ & $44(58.7 \%)$ \\
Osteopenia $(-2.5$ to -1$)$ & $6(7.4 \%)$ & $25(33.3 \%)$ \\
Normal (Higher than -1$)$ & $0(0 \%)$ & $6(8 \%)$ \\
P Value & $<0.001$ & \\
\hline
\end{tabular}

\section{DISCUSSION}

The study showed efficacy of Aclasta in patients with osteoporosis, but its efficacy in women with osteopenia has not been studied much. Hypoestrogenemia is classically associated with decreased bone density and increased fracture rates in approximately $25 \%$ of menopausal women. Most fractures in postmenopausal women take place in those with osteopenia, so therapies that are effective in women with osteopenia are also needed. These types of fractures can be extremely debilitating and lead to many complications. A new 6- 
year, double-blind trial was conducted in 2018, which illustrated Aclasta's role in fracture prevention. It involved 2000 women with osteopenia (defined by a T score of -1.0 to -2.5 at either the total hip or the femoral neck on either side) who were 65 years of age or older (Gass and Dawson-Hughes, 2006; Sözen et al. 2017; Patient education, 29 Sept. 2020). Patients were randomly assigned to a zoledronate $(5 \mathrm{mg})$ group and a placebo group. No supplements or calcium were used. Patients received cholecalciferol $2.5 \mathrm{mg}$ before the start of the study. The primary endpoint were fractures of both the spine and extravertebral fractures. (Rothman et al. 2017; Dhillon, 2016; Dalle Carbonare et al. 2010).

The results of this study showed that women who received zoledronate had a significantly lower risk of fractures (Liu et al. 2015; Mortiz et al. 2019). In the placebo group, fractures were observed in 190 women, in the zoledronate group - in 122 patients (hazard ratio for zoledronate, $0.63 ; 95 \%$ confidence interval, $0.50-0.79 ; \mathrm{P}<0.001$ ). The number of patients requiring preventive treatment of a possible fracture was determined, taking into account the high risk. The calculated value was 15 (Pouresmaeile et al., 2017). In patients treated with zoledronate, the risk of fractures was significantly lower than in the placebo group, including extra-vertebral fractures (hazard ratio 0.66; $\mathrm{P}=0.001$ ), symptomatic fractures (hazard ratio $0.73 ; \mathrm{P}=0.003$ ), fractures vertebrae (odds ratio 0.45 ); $\mathrm{P}=0002)$.

The study found that the use of zoledronate for 18 months significantly reduced the risk of fractures (vertebral and non-vertebral) over the next six years in elderly patients with osteopenia (Lems and Raterman, 2017; Qaseem et al. 2017; Akkawi and Zmerly, 2018).

Both trials illustrated that treatment with zoledronic acid reduces the risk of fractures by approximately two times.

\section{CONCLUSIONS}

Osteoporosis is an urgent public health problem of global importance, since this disease, despite its long latent course, is accompanied by a high level of disability and mortality. The intravenous administration of Aclasta reduced the incidence of new fractures and improved the T-score in patients with osteoporosis who underwent surgery for femoral head fractures, especially in elderly patients.

A positive effect of the use of zoledronic acid in patients with osteoporosis in menopause was found, which was manifested by a significant reduction in the risk of vertebral and extra-vertebral fractures. In addition, a significant increase in bone density was found as a result of therapy with zoledronic acid, which makes it the drug of choice for the treatment of osteoporosis.

\section{ACKNOWLEDGMENTS}

The authors would like to thank the Department of Orthopedics and Trauma Surgery of Thong Nhat Hospital for the support in the research.

\section{CONFLICTS OF INTEREST}

The authors declare no conflict of interest. 


\section{REFERENCES}

Aclasta (zoledronic acid). About this medication. Retrieved from https://chealth.canoe.com/drug/getdrug/aclasta (accessed October 12020 )

Aclasta. Zoledronic acid. Consumer Medicine Information. Retrieved from https://www.medsafe.govt.nz/Consumers/CMI/a/aclasta.pdf (accessed 28 September 2020)

Akkawi I and Zmerly H (2018). Osteoporosis: currentconcepts. Joints. 6(2): 122-127.

Black DM, Delmas PD, Eastell R, Reid IR, et al. (2007). Once-yearly zoledronic acid for treatment of postmenopausal osteoporosis. N. Eng. J. Med. 356(18): 1809-1822.

Black DM, Kelly MP, Genant HK, Palermo L, et al. (2010). Bisphosphonates and fractures of the subtrochanteric or diaphyseal femur. N. Eng. J. Med. 362(19): 1761-1771.

Dalle Carbonare L, Zanatta M, Gasparetto A and Valenti MT (2010). Safety and tolerability of zoledronic acid and other bisphosphonates in osteoporosis management. Drug, Healthcare Pat. Safety. 2: 121-137.

Dhillon S (2016). Zoledronic acid (Reclast ${ }^{\circledR}$, Aclasta $\left.®\right)$ : a review in osteoporosis. Drugs. 76(17): 1683-1697.

European Medicines Agency. (2015). Aclasta (zoledronic acid). Retrieved from: https://www.ema.europa.eu/en/documents/overview/aclasta-epar-summary-public_en.pdf

Gass M and Dawson-Hughes B (2006). Preventing osteoporosis-related fractures: an overview. Am. J. Med. 119(4): 3-11.

Hayer PS, Deane AKS, Agrawal A, Maheshwari R, et al. (2017). Effect of zoledronic acid on fracture healing in osteoporotic patients with intertrochanteric fractures. Int. J. Appl. Basic Med. Res. 7(1): 48.

Ji MX and Yu Q (2015). Primary osteoporosis in postmenopausal women. Chron. Dis. Transl. Med. 1(1): 9.

Lems WF and Raterman HG (2017). Critical issues and current challenges in osteoporosis and fracture prevention. An overview of unmet needs. Therapeut. Adv. Musculoskel. Dis. 9(12): 299-316.

Liu M, Guo L, Pei Y, Li N, et al. (2015). Efficacy of zoledronic acid in treatment of osteoporosis in men and women-a meta-analysis. Int. J. Clin. Experiment. Med. 8(3): 3855-3861.

Lyles KW, Colón-Emeric CS, Magaziner JS, Adachi JD, et al. (2007). Zoledronic acid and clinical fractures and mortality after hip fracture. New England J. Med. 357(18): 1799-1809.

Miller PD, Pannacciulli N, Brown JP, Czerwinski E, et al. (2016). Denosumab or zoledronic acid in postmenopausal women with osteoporosis previously treated with oral bisphosphonates. J. Clin. Endocrin. Metabol. 101(8): 31633170.

Moritz M, Knezevich E and Spangler M (2019). Updates in the treatment of postmenopausal osteoporosis. U.S. Pharmacist. 44(9): 32-35.

Nguyen ND, Eisman JA and Nguyen TV (2006). Anti-hip fracture efficacy of bisphosphonates: a Bayesian analysis of clinical trials. J. Bone Min. Res. 21(2): 340-349.

Patient education: Bone density testing (Beyond the Basics). Retrieved from https://www.uptodate.com/contents/bonedensity-testing-beyond-the-basics (accessed 29 September 2020).

Pouresmaeili F, Kamalidehghan B, Kamarehei M, and Goh YM (2018). A comprehensive overview on osteoporosis and its risk factors. Therapeut. Clin. Risk Manag. 14: 2029-2049.

Qaseem A, Forciea MA, McLean RM and Denberg TD (2017). Treatment of low bone density or osteoporosis to prevent fractures in men and women: a clinical practice guideline update from the American College of Physicians. Ann. Internal Med. 166(11): 818-839.

Reid IR, Horne AM, Mihov B, Stewart A, et al. (2018). Fracture prevention with zoledronate in older women with osteopenia. N. Eng. J. Med. 379(25): 2407-2416.

Rothman MS, Lewiecki EM and Miller PD (2017). Bone Density Testing Is the Best Way to Monitor Osteoporosis Treatment. T Am. J. Med. 130(10): 1133-1134.

Siris ES, Harris ST, Rosen CJ, et al. (2006). Adherence to bisphosphonate therapy and fracture rates in osteoporotic women: relationship to vertebral and nonvertebral fractures from 2 US claims databases. Mayo Clinic Proceedings. 81(8): 1013-1022.

Sözen T, Özışık L and Başaran NÇ (2017). An overview and management of osteoporosis. Eur. J. Rheumatol. 4(1): 46.

Sosa Henríquez M, Groba Marco M and Díaz González JM (2010). Zoledronic acid in the treatment of osteoporosis. Rev Osteoporos. Metab. Miner. 2(4): 21-30. 